\title{
Problems and Prospects with the Scientonomic Workflow
}

\author{
Jamie Shaw \\ Ted Rogers School of Management, \\ Ryerson University \\ jamie.shaw@ryerson.ca
}

\author{
Hakob Barseghyan \\ IHPST, \\ University of Toronto \\ hakob.barseghyan@utoronto.ca
}

\section{Keywords}

scientonomic workflow, traditional workflow, transparency, inclusivity, epistemic goals, acceptance, pursuit, commenting, publish-or-perish model, mechanism of closure, consensus formation, ripple effect

\section{Abstract}

While the scientonomic workflow guiding the development of a general theory of scientific change has been practiced for nearly four years, it has yet to be formally evaluated. The goal of this paper is to fill this gap with a critical appraisal of the practice and theoretical underpinnings of the workflow currently used in scientonomy. First, we consider the traditional workflow which uses publications as the primary vehicle for substantive epistemic change and find that it fails to be sufficiently transparent or inclusive and is ambiguous at decisive points. Conversely, as we argue, the scientonomic workflow has the potential to succeed where the traditional workflow fails and thus provides a promising alternative workflow. We then go on to note a number of practical and theoretical problems that have arisen upon reflection on the scientonomic workflow and suggest some modifications to the workflow and to our practices. This paper takes the first steps in improving the workflow to reach its maximum potential. 


\section{Introduction}

The current scientonomic workflow is both well-known within the community and, simultaneously, not wellstudied. Despite the workflow being the backbone and primary means by which critical discussion is directed within the community, there remain methodological and practical questions that must be answered to make it viable in practice. This paper launches what will, hopefully, be a series of critical discussions about the current scientonomic workflow. The purpose of this paper is twofold. The first is to provide an outline of the kinds of considerations that underpin the workflow's functionality. The second is to highlight some issues with the current workflow and motivate a number of modifications which we hope will allow it to live up to its potential.

This paper will begin by contrasting the scientonomic workflow with the traditional workflow often used within the humanities and sciences. The shortcomings of the traditional workflow, which have recently been revealed, provide criteria for an implementable workflow. In the second section, we briefly recapitulate the scientonomic workflow and show how it meets the aforementioned criteria. In the third section, we outline some obstacles facing the scientonomic workflow that obstruct its ability to fully fulfill these criteria. We conclude with some proposed modifications to the workflow.

\section{The Traditional Workflow and its Problems}

The primary means of transmitting information within intellectual communities has been, especially since the 1960s, publications in academic journals (Csiszar, 2018). The journal was, by and large, an invention of the $18^{\text {th }}$ century. Before this, and during the early stages of the journal, there were many ways of communicating, disseminating, and discussing ideas including personal correspondences and in-person conversations. While these and other means (e.g. conferences, phone/e-mail conversations, videos) are still used, they have become marginalized as legitimate means of conveying information and, instead, publishing in academic journals has become the primary facilitator of the growth of knowledge. Emerging technologies and increased global communication infrastructure allowed for journals to flourish in a wide variety of disciplines. This became even more prominent and ingrained given institutional pressures to "publish or perish" and the advent, and increased popularity, of the world wide web.

This traditional workflow is publication-centric. Its workings will be familiar to most academics, such that we need not go into great detail here. The workflow begins with the composition of a draft which is eventually submitted to a journal. If the editor of the journal considers this draft to be above a minimal threshold of quality, and to fall within the boundary conditions of the journal, it is passed on to reviewers who evaluate the paper. In some circumstances, the paper is rejected, while in others it is published, possibly with revisions. When the paper is published, it is made available to other academics and disseminated through the community at large.

Despite its dominance, it is becoming increasingly evident that the traditional workflow suffers from severe shortcomings. The result of this has been a proliferation of alternative workflows including increased activity within the blogosphere, archives with limited peer review, "post-publication review" (see Hunter, 2012 for a rough-and-ready depiction of this approach), and so forth (see Birukou et al., 2011). The scientonomic workflow is another proposed alternative to the traditional workflow. While the critical literature is immense and difficult to summarize, there are a few common lines of argument that can be extracted:

1. The traditional workflow is insufficiently transparent.

2. The traditional workflow is ambiguous, in practice at least, as to its goals.

3. The traditional workflow is largely exclusive.

The first point has several facets. First, the process of peer review often happens behind closed doors. The peer reviewers' comments, and the draft adjustments that ensue, are only visible to the reviewers, editors, and the authors. This leaves open the possibility that ideas in the initial draft become forgotten and remain unavailable for general discussion by the larger community (see Ritson, 2016). Second, large numbers of papers that are (outright) rejected for publication never see the light of day in print or, if they do, are published in low-visibility journals. This eliminates many papers that may still be of interest to the general community even if they do not 
meet the high standards of top-tier journals. This problem is amplified by swarms of studies that suggest that peer review is conservative and makes it difficult to publish unorthodox or alternative ideas (see Stanford, 2019 and the citations therein). Finally, some studies have suggested that extremely large proportions of published papers go unread and make little to no discernible impact on the community. In one study, it was suggested that not only are $90 \%$ of publications uncited but "as many as $50 \%$ of papers are never read by anyone other than their authors, referees and journal editors" (Meho, 2007, p. 32). That's 900,000 papers in 2007 that were not read by anyone beyond the peer review process. This is partially due to the fact that many researchers do not have the means to access certain journals, and the exponential and quantitative growth of research output.

The second point is on display when one consults the purpose of peer review. In scientonomic terms, are peer reviewers evaluating papers for the pursuitworthiness or acceptability of the content of the paper? The answer to

There may be other stances reviewers may take towards publications, but to elucidate them properly, changes would need to be made to the currently accepted taxonomy of epistemic stances. this question is far from obvious, as many qualitative studies suggest that it is unclear which it is. Some reviewers review for pursuitworthiness, while others evaluate for acceptance (see Lee, 2015, p. 1276). Some reviews unwittingly include elements of both. This problem leads to a corollary: how should we understand the content of the publications themselves? Should we understand publications as containing knowledge accepted by the respective epistemic community or merely as containing ideas that were considered interesting, i.e. pursuitworthy by the editors and reviewers? Many of our practices suggest that it might be the former. For example, in Naomi Oreskes' widely cited study on the consensus on climate change, she uses the content found in publications as a measure of acceptance (Oreskes, 2004). Moreover, many reviews reject papers due to their

Here, acceptance comes at the level of aggregating findings in individual publications to a community level consensus. The implicit idea here is that each publication represents acceptance to a local subcommunity (the author(s) and, perhaps, the reviewers and editor) and, when compiled, provide a stronger kind of acceptance shared by the community at large. purported flaws suggesting that they should not be published because they are not acceptable (Byrne, 2000). Yet, at other times, the fact that something was published is only taken to mean that it was considered to be worthy of further attention. Philosophers, for example, will be acutely familiar with this view: no one reads the newest

paper on realism in Philosophy of Science to see what the community believes about realism. They merely search for stimulating and interesting ideas.

Finally, the process of peer review is often exclusive in the sense that it only involves the participation of a small fraction of the community. Let's say the goals of peer review are evaluations for acceptance. If this is the case, then acceptance is determined by a small handful of reviewers and, possibly, some nosy editors. The assumption underlying the traditional workflow is that these reviewers will be representative of the community at large. But this assumption is nearly always problematic since communities are often replete with disagreement about what is acceptable. This is seen acutely in the case of peer review using the notion of "single-rater reliability" defined as the "correlation between two independent assessors' ratings of the same submissions across a large number of different submissions" (Marsh, Jayasinghe, \& Bond, 2008, p. 162). The findings of various journals across the sciences and humanities varied from .17 to .54 ; all fall drastically below the acceptable rate of .8-.9 (ibid). One landmark study shows just how extreme this can get. In this study, the authors resubmitted papers that were already published in prestigious journals and well-cited. Astonishingly, only $8 \%$ of reviewers noticed that these were resubmissions. What is even more revealing is that $89 \%$ of the already published and wellrespected papers were rejected (Bartko, 1982). Thus, the assumption that reviewers are somehow representative of the community at large is suspect. More specifically, the majority of peer reviewers are the "elite" whose views are inconsistent with newly emerging research done by younger generations (Musselin, 2013). On the other hand, let's say that the goal of peer review is to evaluate for pursuitworthiness. This fares no better for the same reason, in the sense that a small portion of the community determines which ideas are worthy of discussion and further elaboration. This often funnels discussion into a few topics which are often determined by the established elite who are the most summoned as peer reviewers (see Phillips, 2011). Moreover, even if we radically loosened our criteria of pursuitworthiness, it would raise a distinct problem of wherein accepted knowledge resides. If 
publications were reviewed merely for pursuitworthiness, then the resulting scholarly literature would simply be an assortment of (possibly) interesting, i.e. pursuitworthy, ideas. In that case, how would we know what is accepted by the community at that time? If publications were merely pursuitworthy ideas, we wouldn't be able to use them as textual sources that indicate theory acceptance. This would lead to a new version of the problem of transparency. Namely, we would have lost the ability to straightforwardly discover what is accepted by a given community at a given point in time. This would

Indicators of theory acceptance are textual sources that represent the position of a scientific community regarding a theory at some time (Barseghyan, 2015, pp. 113-120). Useful indicators are contextual to time and culture (Fatigati, 2017). They might include encyclopedias, textbooks, university curricula, minutes of association meetings, etc.

also mean that there is no straightforward mechanism for

contributing towards a body of accepted knowledge by proposing modifications to what is currently accepted.

In short, the traditional workflow is flawed, which suggests that a new and more promising workflow is in order. We suggest that the failures of the traditional workflow can be turned into criteria for a good academic workflow. These criteria are:

1. A workflow should be transparent.

2. A workflow should be inclusive.

3. A workflow, insofar as it employs peer review, should have clearly stated epistemic goals.

In short, an academic workflow should provide a transparent, inclusive, and clearly articulated mechanism for the advancement of accepted knowledge.

In the following section, after briefly recapitulating the scientonomic workflow, we will show how it meets these standards.

\section{The Advantages of the Scientonomic Workflow}

To remedy the flaws of the traditional workflow, in 2016, the scientonomy community devised and implemented a new academic workflow geared towards a piecemeal and transparent advancement of the body of communal knowledge. To facilitate this new workflow, the community established the Encyclopedia of Scientonomy as a repository of the communal body of knowledge and a new peer-reviewed academic journal, Scientonomy: Journal for the Science of Science. It also clarified the respective goals of workshops and seminars. Here is a standard summary of the key stages of the workflow:

- Pose Questions: The task of this stage is to scrutinize the current body of communal knowledge and identify as many open questions as possible. This is accomplished in focused seminar discussions, conferences, and publications.

- Suggest Modifications: The task of this stage is to advance our communal knowledge by proposing modifications to it. Once published, these suggested modifications are properly documented on the respective pages of the encyclopedia of scientonomy. Although modifications are currently published exclusively in the journal of scientonomy, in principle, they can be published in any journal which makes use of the scientonomic workflow.

- Evaluate Modifications: The task of this stage is to assess the suggested modifications and decide which of these suggested modifications are to be accepted This is done communally on the respective discussion pages of the encyclopedia. Once the community reaches consensus, the communal verdict is documented, and the respective pages of the encyclopedia are modified. If a suggested modification causes disagreement, it is further discussed at workshops, with the goal of arriving at consensus.

- Document Changes: The task of this stage is to document changes in our knowledge. If a modification is considered acceptable by the community, the respective articles of the encyclopedia are modified to reflect that change. If a modification is considered unacceptable, then the respective verdict is documented for that modification.

Here is a traditional diagrammatic depiction of the scientonomic workflow: 


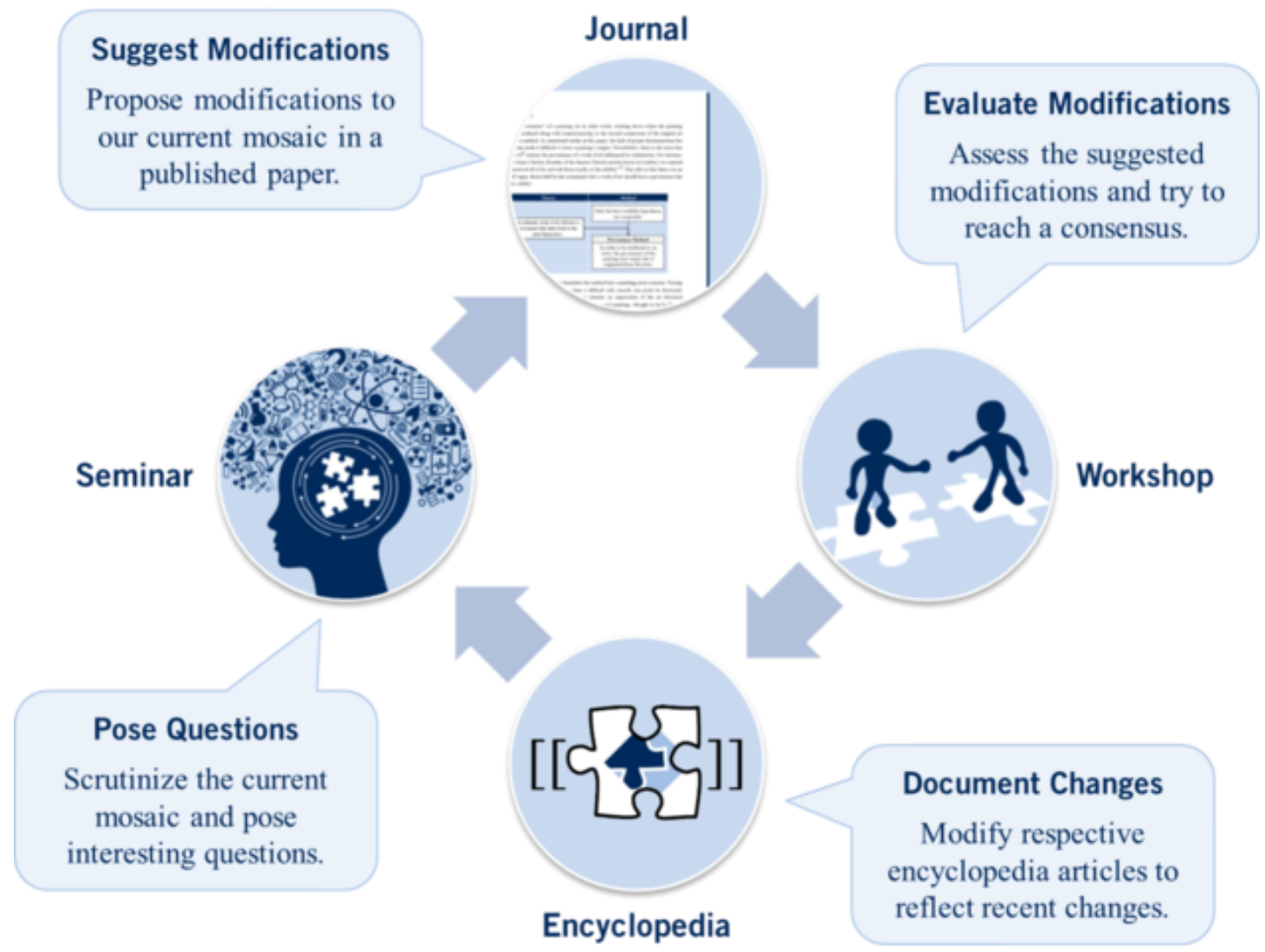

One great advantage of this workflow is that, at any moment of time, the community has a very good idea as to where it stands, what theories it currently accepts, what open questions it tries to answer, what modifications have been proposed, and how they have been evaluated. The scientonomic workflow attempts to meet the criteria listed at the end of the previous section in the following ways.

First, the workflow is more transparent than the traditional workflow in the sense that it allows for members of the community to see how the theory of scientific change develops. All discussions on whether or not a proposed modification is to be accepted are visible on the respective pages of the encyclopedia. Members of the community can revisit these discussions when consulting why a proposed modification was accepted/rejected or consult a current discussion when participating in deciding whether it should be accepted. Moreover, the encyclopedia lists all the changes to the communal body of knowledge and summarizes the verdicts of the community regarding each and every suggested modification. Importantly, the workflow ensures that both communal consensus and disagreement are properly documented and are readily accessible to the whole community. As a result, it is always clear where the community stands on a given topic since all accepted knowledge on the processes of scientific change is documented in the encyclopedia.

Second, the scientonomic workflow aims to be inclusive. All members of the community can participate in deciding whether or not a proposed modification should be accepted. This is in striking contrast with the traditional workflow where a mere handful of scholars - editors and reviewers - decide the fate of an idea. Suggested modifications are accepted only when, following a period of communal discussion, the community decides that the modification is acceptable. This is geared towards maximizing community participation in shaping and reshaping the accepted body of knowledge. Moreover, the community is loosely demarcated by those who have an account on the encyclopedia; this permits the community to grow with ease and expands the degree of inclusivity as others join the community. Thus, the workflow allows for an inclusive assessment of how our theory of scientific change is to advance. 
Naturally, not all the steps of the workflow are transparent or inclusive. As the editorial process of the journal itself follows the traditional format of peer review, the process of proposing and publishing suggested modifications is not as transparent or inclusive as the other parts of the workflow. Designers of a workflow especially the one that aims to be transparent - have a difficult decision to make at this stage. On the one hand, they can opt for a complete transparency and inclusivity of the publication process, but this may come at the expense of jeopardizing the whole idea of anonymous peer reviews. As a result, any half-baked or even unbaked ideas can enter the market without even minimal quality assurance. On the other hand, they can stick to the usual anonymous (i.e. non-transparent) peer review process where experts evaluate for pursuitworthiness (i.e. notinclusive). This way the workflow will have some level of quality assurance, but it will also bring some unavoidable opaqueness and exclusivity.

It is clear that the current scientonomic workflow has opted for the latter option. This means that, just as in the traditional workflow, the decision to publish or not to publish a suggested modification is made by the editors and reviewers. Anyone who participated in editing or reviewing submitted papers will attest to the fact that it takes a lot of work and effort to bring a half-baked idea to a publishable, i.e. baked, stage. Naturally, this imposes a limitation on which ideas make it into the market. Yet, the underlying assumption here is that some basic filtration is an absolute necessity, for otherwise the pursuitworthy ideas would be crowded out on the market by a whole bunch of ideas that show lack of research, lack of scientonomic knowledge, include contradictions, are poorly formulated, or all of the above. Thus, it is important to have some checks in place to ensure that the papers show proper knowledge of the current state of scientonomy, and that the suggested modifications are formulated in a clear and succinct a fashion so that their evaluation by the community is as smooth as possible.

Third, in the scientonomic workflow, the goals of peer review are straightforward: peer review merely assesses a paper for pursuitworthiness of the modifications suggested in the paper. Acceptance is determined - at least in principle - by the community, not the reviewers or editors of the journal.

However, while this is standard practice, it remains to be

In the three years following its implementation, the codified. This will be revisited in the final section.

workflow has facilitated a considerable transformation of our communal body of knowledge. As of November 1, 2019, it has produced 39 suggested modification of which 19 have become accepted, leading to the acceptance of new formulations of the third and second laws (Sebastien, 2016; Patton, Overgaard, \& Barseghyan, 2017), the notion of authority delegation (Overgaard \& Loiselle, 2016; Loiselle, 2017), a definition of community (Overgaard, 2017), as well as a whole new ontology of scientific change with questions and theories as two fundamental epistemic elements (Rawleigh, 2018; Barseghyan, 2018). Our communal answers to some questions have already changed more than once during this period (e.g. the notion of theory acceptance, the ontology of epistemic elements).

In short, the advantages of the workflow are clear: with its intended transparency, inclusivity, and clearly articulated goals, the workflow allows for the piecemeal advancement of our communal knowledge. Not only do we always know where we stand as a community, we also know the avenues for modifying the theory further and changing the mosaic of the scientonomy community.

\section{Problems for the Scientonomic Workflow}

The fact that the scientonomic workflow has these emerging advantages demonstrates its promise as a workflow. Given that these advantages are quite general, it is possible that other fields may ultimately benefit from a similarly styled workflow. Here, we wish to highlight problems for the workflow as it is currently practiced. Our new workflow is still a work in progress and has yet to fully live up to its intended goals. We seek a constantly improving workflow, just as we seek a constantly improving knowledge of scientific change. Indeed, if we believe that our knowledge of scientific change is to be advanced in a piecemeal and transparent fashion, the same should apply to the mechanics of our workflow. Here, we propose four pressing problems facing the workflow today. 
The first problem appears to be a lack of commenting on suggested modifications. As it stands, the vast majority of the participation in the encyclopedia discussions is done by a select few members of the community. The result of this is that the theoretical advantage of inclusivity of the workflow have not yet been realized in practice. We could have inclusive determinations about the advancement of the scientonomic mosaic, but for the most part we do not, simply because of a lack of participation. This has an unfortunate spillover effect. It entails that if there is no discussion, there is no progress via changing the accepted theory. Proposed modifications sit around, waiting to be discussed, and the status quo remains. Of the 39 proposed modifications, 19 remain open as of November 1, 2019. Of these open modifications, 12 are yet to receive a single comment, with some modifications dating back to early 2017 ! The lack of participation thus leads to a conservative enterprise where changes to the mosaic happen slowly, if at all.

This problem is forced on us by the current academic setting with its virtually exclusive incentivization of publications. In the current "publish or perish" climate, publications are the main driver of success in an academic career. As aptly noted by Camille Paglia almost three decades ago (Paglia, 1992, p. 237):

The postwar "publish or perish" tyranny must end. The profession has become obsessed with quantity rather than quality. At top universities, two published books are becoming the minimum even for an associate professorship.

The sentiment is echoed by Nobel laureate Peter Higgs (Aitkenhead, 2013):

Today I wouldn't get an academic job. It's as simple as that. I don't think I would be regarded as productive enough.

The "publish or perish" culture has many unfortunate consequences which we won't discuss here (for a discussion, see Gad-El-Hak, 2004). What is important for our purposes is that it provides virtually no incentive for academics to devote the time and effort to properly analyze suggested modifications and comment on them on the respective pages of the encyclopedia. Since commenting on modifications does not result in anything tangible for the commentator, the community often lacks the motivation to comment. While we agree with most of the criticism of the "publish or perish" culture, we in the scientonomy community currently lack means of substantially affecting the larger academic setting. This means that we should find a way to either incentivize commenting within the current setting or modify our workflow in such a way that the progress of our field doesn't stale in the absence of comments.

The second problem with the current workflow is that the commentators of a suggested modification are currently not allowed to reformulate any of the original theories and questions suggested by the author of that suggested modification. It sometimes happens that, during discussions concerning a suggested modification, commentators suggest alternative formulations which the community finds advantageous and is prepared to agree on. However, such a scenario is currently not allowed by the scientonomic workflow, as the commentators are not allowed to offer edits to the original formulation suggested by the author. The current workflow stipulates that any alternative formulation should come in a paper of its own, be registered as a new suggested modification, and evaluated accordingly. This is problematic, as at times a compromise might be easily achievable through a simple change in the original formulation. Nowadays, even if all the parties agree that a little tweak to the original published formulation would solve the problem, the workflow doesn't permit such a course of action. Among other things, this creates an unnecessary bottleneck, where an emerging communal consensus cannot be registered in the encyclopedia due to the limitations of the workflow.

The third problem is that of ripple effects. As suggested modifications become accepted, they often imply changes to elements of our mosaic that are not explicitly mentioned in the respective suggested modifications. Consider, for example, modification Sciento-2018-0005 (Barseghyan, 2018) which proposed a new definition of method as a set of criteria for theory evaluation, and a new definition of methodology as a normative discipline that formulates the rules which ought to be employed in theory assessment. It was noted by Paul Patton and

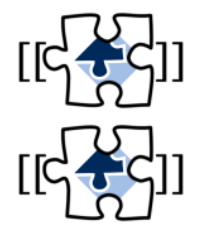


accepted by other members of the community that the acceptance of these new definitions will require a series of changes to other elements of the scientonomic mosaic, such as the methodology can shape method theorem. Ideally, a modification should identify all instances where old theories and old encyclopedia entries need to be modified once it becomes accepted. However, neither our authors nor our editors are omniscient, which means that it is quite possible that at least at times they may not be able to identify all the necessary changes to old theories implied by the modification. Additionally, they may make the wrong judgment when suggesting what changes need to be made. As a result, some of these implied changes become evident only after the publication or even after the acceptance of the respective modification (e.g. modification Sciento-2018-0008). This raises an important question concerning the handling of such ripple effects: how should they be dealt with? Specifically, does this mean that the editors of the encyclopedia have the right to introduce these additional changes - at least if these are small changes - to the respective encyclopedia pages for the sake of consistency and clarity? Or, alternatively, should these additional changes be presented as new suggested modification and handled through the standard mechanism of discussing them on their respective encyclopedia pages?

The fourth and final problem which we would like to discuss here is that the current workflow is ambiguous as to what constitutes a consensus and how exactly it is to be achieved. The existing practice implicitly conceives of consensus as a lack of explicit objection. Currently, if a suggested modification has comments and none of those comments is criticizing the modification, it becomes accepted. We have been using roughly the same approach as the Navaho as described by Kluckhohn and Leighton (Kluckhohn \& Leighton, 1974, pp. 100-101):

The native way of deciding on an issue is to discuss it until there is unanimity of opinion or until the opposition feels it is no longer worthwhile to urge its point of view.

Recent literature has revealed problems with this approach in similar examples of consensus formation (Novak, 2010; Urfalino, 2014; Beatty, 2018). There is a wide variety of reasons why people may not want to object to a modification explicitly, yet they still may not want to accept that modification. Some people may not wish to comment because they do not want to be seen as stalling the acceptance of a modification. Some (especially junior scholars) may not feel comfortable criticizing a proposed modification from a more senior or powerful member of the community. In a different vein, some participants have more "tenacity" when debating proposed modifications. Some participants back down in a debate not because their arguments have been addressed, but because they grow tired of arguing in what feels like a futile debate. Additionally, the current practice of the scientonomic workflow has no timeline for when objections must be raised by. This allows for a couple of potential problems: one where a paper's suggested modifications are accepted too quickly before dissensus is able to emerge and another where we never accept anything a paper suggests because we are waiting for dissent to (possibly) arrive. While some modifications seem to be accepted rather in a few months of their publication, others take years to have a verdict despite the fact that they don't generate much dissent. Thus, without any time limit or any proper closure mechanism in place,

We'd like to thank an anonymous reviewer for pointing this out to us.

modifications can be accepted either too quickly or be simply "forgotten" by the community.

For these reasons, and others, consensus by lack of objection seems like a problematic approach. This problem is likely to become amplified as the community grows. As the community is mostly composed of colleagues at the University of Toronto who have (mostly successful) histories of working together on a number of projects, the problem isn't as pronounced as it could be. But when the community expands to include more people and, possibly, more prestigious researchers and strangers, this problem may become even more salient in the future.

Importantly, we do not claim that this list of problems is exhaustive. There might be many other issues with the workflow that may become apparent as the community grows and involves a greater number of scholars. Specifically, at this stage, it is unclear how scalable the workflow is, as approaches that work in a small community may or may not work on a large scale. Thus, a series of open discussions are required to detect and pre-empt at least some of the possible scalability bottlenecks. This reinforces the need for an ongoing reflection upon our workflow. 


\section{Changes to the Workflow}

Unfortunately, we do not have definitive solutions for all of these problems. However, we would like to propose a few modifications to the current workflow which may increase its functionality. Ironically, and fortunately, the workflow allows for its own self-improvement. We will survey a few possible proposals, so readers will have alternatives to consider, while advancing our own opinion on the matter. The first proposal, though, we expect to be relatively uncontroversial: we would like it to be explicitly accepted that the goal of peer reviews in the journal of scientonomy is evaluation for pursuitworthiness rather than for acceptance. The journal uses a number of standard email templates to contact potential reviewers; we suggest including a few lines in these emails clarifying the goals of the peer review. Similarly, we suggest editing the respective pages of the encyclopedia to explicitly state the goal of peer reviews in the scientonomic workflow.

The problem of the lack of comments can be addressed by restructuring incentive structures. As is well known, the current incentive structure imposed on many members of the community is to publish and present at prestigious venues. Spending time and effort discussing topical issues in scientonomy on the encyclopedia does little for one's CV. A few suggestions can be raised here. However, these suggestions should not be seen as modifications of the workflow per se since they require no formal changes to the workflow. They require changes to our practices. One incentive may be to offer a book prize for extensive participation on the encyclopedia. This prize is a CV-worthy line and also provides material incentive to participate. A downside of this approach is the cost and where the funds will come from. Another, potentially complementary, suggestion may be to introduce star-ratings. Surprisingly, studies suggest that people are strongly encouraged to participate more when they achieve some kind of status as a result. Moreover, a "5 Gold Star" rating may well provide a CV line as well. One disadvantage of this is that it seems far-fetched, but this depends on how the community feels about this suggestion.

A more radical solution to lack of commenting was suggested by Karen Yan at the $1^{\text {st }}$ Scientonomy Conference in May 2019 in Toronto. Yan's idea is to reach out to scholars working on a given topic and invite them to participate in arguments for or against a proposed modification, with the goal of publishing the ensuing discussion in a separate article of the journal or an edited volume. Of course, other scholars can also contribute to the discussion, but this suggestion ensures that there will be discussion. It also contributes to the growth of the community by involving outside specialists in our discussions. This allows for additional feedback that may not have been raised by active members of the scientonomy community.

As for the problem of not permitting reformulations of original suggestions in the comments, our solution is twofold. First, we suggest removing the bottleneck and allowing reformulations of original formulations in the comments. However, this will require publishing the resulting new formulation, so that the new formulation is properly documented, and the credit is given to the respective authors. Thus, our second suggestion - which is complimentary to Yan's suggestion above - is to publish the ensuing discussion in a separate paper that will culminate with the new formulation the community agreed upon. An approach similar to this has been successfully implemented in Behavioral and Brain Sciences journal, among others, which publishes not only original research articles but also the commentaries of specialists on these articles and the responses of the authors. Specifically, we think it will be a good idea to publish the discussions on all modifications once a communal verdict is available as a separate paper co-authored by all participants of the discussion. An alternative to this approach would be to only publish those discussions which led to significant changes in the original formulation. This alternative solution may inadvertently incentivize dissent and disagreement for the sake of getting published. We are against this alternative as we believe that our workflow should incentivize agreement and disagreement equally. Thus, by publishing all discussions, we incentivize all commenting without skewing the incentive towards disagreement.

To separate these commentary papers from original research papers, we suggest using a slightly different page numbering, for instance, prefixing page numbers with letter "c" (e.g. c1, c2, c3, etc.). The editorial process for these papers will involve a few straightforward steps, including polishing comments and removing "fluff", adding references where necessary, writing a short verdict which will culminate both the commenting paper and the 
respective encyclopedia page. Importantly, these papers won't require any additional peer reviewing, as they don't contain original research. If a discussion yielded a new formulation, any such formulation will be clearly stated in the commentary paper and added to the respective modification under a separate sub-heading (e.g. by separating between "Original Suggestion" and "Final Suggestion", or something to that effect). We also believe that, by default, the new formulation should bear the original author's name, unless the author decides to give credit to those who significantly contributed to the new reformulation. This should be decided collegially by the author, the commentators, and the editors on a case-by-case basis.

Our next suggestion concerns the mechanics of handling ripple effects. We believe that our handling of ripple effects should depend on whether the additional change is implied by the modification or whether it is conceivable to accept the modification without accepting the additional change.

Those of us who have worked on the encyclopedia of scientonomy know that ripple effects often concern changes that have been simply overlooked by the authors and/or editors during the process of formulating the suggested modification. These are fairly trivial changes that are implied by the respective suggested modification and don't warrant a separate discussion. For instance, following the publication of Rawleigh's paper on questions (Rawleigh, 2018), the editors of the encyclopedia had to register Rawleigh's suggested modifications in the encyclopedia, which required a creation of several Topic and Theory pages concerning the ontology of scientific change. It became obvious that we had accepted a whole layer of theories concerning the ontology of epistemic elements, epistemic stances, and epistemic agents - theories which we hadn't properly articulated in the encyclopedia. As a result, we had to create the respective encyclopedia pages, for without such pages we would not have been able to register Rawleigh's suggested modifications. The ripple effects caused by the acceptance of Barseghyan's redrafted ontology (Barseghyan, 2018) were handled in a similar fashion. Specifically, when it became accepted that normative theories of all kinds have a capacity of being employed (modification Sciento2018-0008), it implied that there are no additional epistemic stances that can be taken exclusively towards methods, i.e. since methods are a subtype of normative theory, all the epistemic stances that can be taken towards normative theories can also be taken towards methods. As such, this specific consequence of the redrafted ontology had not been explicitly stated in the respective suggested modifications. Yet, it was obvious that such a change had been clearly implied. Consequently, a few additional pages were created in the encyclopedia to handle this ripple effect. Among these are pages Epistemic Stances Towards Methods, Epistemic Stances Towards Methods - None (Barseghyan-2018), Epistemic Stances Towards Norms, and Epistemic Stances Towards Norms - Employment (Barseghyan-2018). This is clearly stated in the Acceptance Indicators of the respected theories.

Our suggestion is to make this practice explicit and grant the editors official housekeeping rights so that they can create the necessary pages of the encyclopedia provided that these pages do not alter the accepted body of scientonomic knowledge, but merely explicate what is implicitly accepted by the community. For all other cases (i.e. for cases when changes go beyond what is implicit in the suggested modification), we propose that additional changes must be introduced in an orderly fashion: they should be registered by the editors as new suggested modifications so that the community can discuss and evaluate them. The key rule of thumb here is this: is it conceivable to accept the modification without accepting the ripple effect change in question? If so, then this new ripple effect change should be registered as a new suggested modification and discussed. If not, then no new suggested modification is necessary; instead, the editors should modify the encyclopedia to document the ripple effect.

As for the problem of consensus formation, there are a few directions which can be taken. Each of these solutions takes the form of a mechanism of closure, a notion that has been discussed extensively in the literature in science and technology studies and public policy (Horst, 2010; Franco, Rouwette, \& Korzilius, 2016; Goode, 2016). While views differ as to how closure should proceed, they agree that we need some way to close debates or discussions such that they do not extend indefinitely. Although we may not be able to reasonably expect complete agreement on a given suggested modification, even given extended periods of time and transparency, we must have some pre-agreed upon way of closing debates to make progress. Otherwise, there would just be 
endless debate. Here are a few ideas that have been mentioned in this literature which may be applicable in case of the scientonomic workflow.

The first would involve a majority vote. This could go along different lines, such as a simple majority $(50 \%+1)$, or supermajority of three fifths $(60 \%)$, two thirds $(67 \%)$, or three quarters $(75 \%)$. The idea entails that after a certain amount of time has passed such that there have been ample grounds for open discussion, a vote is taken. This vote will be offered to all members of the community, who will be given a short timeframe to decide. This strategy allows for reintroducing larger amounts of the community into the workflow while not imposing a great deal of work - thus aiding in the problem of a lack of proper incentives to contribute to online discussions. In a sense, this proposal would look like an election where there are two main phases. In the first phase, arguments will be made but no particular line of action will be taken. In the second phase, the vote will take place and a decision will be made by the will of the people. In addition, this strategy has the advantage of overcoming the problem of masked objections. People can vote anonymously, expressing their view and approval or dissatisfaction with a proposed modification, without fear of any sort of reprisal. One disadvantage is that a vote is not always grounded in good reasons. Community members may ignore important considerations and vote without being informed on the topic, thus leading to a less-than-ideal consensus. As we are witnessing in the world around us, the will of the people does not always pick out the best choice.

Another proposal would be to introduce a "countdown" mechanism for achieving closure. The idea would be to provide a three-month (90-day) window for discussion to occur. If there are no dissenting views within this timeframe, then the proposed modification is accepted by default. If there are objections raised within this timeframe, the countdown is stopped, and we continue the discussion until a consensus is reached. This allows for the possibility of inclusive debate without stalling on the development of our theory of scientific change. One disadvantage is that it doesn't address the worry about masked objections raised in the previous section - people still may not explicitly dissent.

Naturally, we do not intend this list of suggestions to exhaustively solve all the extant problems with the workflow. These are just some of the modifications which, we think, can help improve the workflow. Clearly, there could be many alternative ideas that might be worth pursuing. One such idea, suggested by our reviewer, is to mimic the arXiv's workflow and publish the suggested modifications as pre-prints in an open-access journal. Whether this or any other alternative suggestions can further improve the workflow remains to be seen. At this stage, we hope to provoke a critical reflection on our workflow and spark a series of discussions with the goal of its piecemeal and transparent advancement.

\section{Concluding Remarks and Future Questions}

Given that the growth of the scientonomy community is desirable, we must bear in mind what changes the workflow must have to undergo in the future. Can we expect to manage consensus-forming discussions as the community grows and becomes more diverse? More generally, how scalable is our workflow? Will workshops be manageable as the community becomes more geographically dispersed? Can we expect top-quality articles addressing the increasingly large variety of open questions to continue to be submitted to the journal? These questions, and many others, will become prominent as the community grows. It behooves us to keep our eyes open on how the workflow can continue to be effective at meeting the aforementioned criteria as the situation changes. However, given that these questions are not of immediate priority, we have sidelined them in this paper, though they are still worth thinking about. In the meantime, we hope to have suggested some modifications to take some steps towards a workflow worth having.

\section{Acknowledgments}

We would like to thank Paul Patton and an anonymous reviewer for their insightful comments and helpful suggestions. 


\section{Suggested Modifications}

Thus, we would like to record the following suggested modifications to our workflow with a hope that they will be extensively discussed and commented on:

\section{[Sciento-2019-0001]}

Accept that the goal of peer reviews in the scientonomic workflow is evaluation for pursuitworthiness rather than acceptability.

\section{[Sciento-2019-0002]}

Accept that the discussions concerning a suggested modification are to be published once a communal verdict is available. The discussions are to be published in the journal as special commentary articles co-authored by all participants of the discussion or in special edited collections.

\section{[Sciento-2019-0003]}

Accept that the commentators of suggested modifications are allowed to suggest reformulations of the original formulations.

Also accept that, by default, the new formulation should bear the original author's name, unless the author decides to give credit to those who significantly contributed to the new reformulation. This should be decided collegially by the author, the commentators, and the editors on a case-by-case basis.

\section{[Sciento-2019-0004]}

Accept that an annual book prize is to be offered for extensive participation on the encyclopedia. The winner(s) are to be decided by the encyclopedia editors.

\section{[Sciento-2019-0005]}

Accept that star-ratings are to be introduced for commentators who comment on suggested modifications on the encyclopedia.

\section{[Sciento-2019-0006]}

Accept that the encyclopedia editors are to be granted official housekeeping rights to handle the ripple effects.

Also accept that if the additional required changes are implicit in the suggested modification, the editors should create and alter encyclopedia pages to ensure that the accepted body of scientonomic knowledge is properly documented; if it is conceivable to accept the modification without accepting the ripple effect change in question, the editors should register these changes as new suggested modifications so that the community can discuss and evaluate them in an orderly fashion.

\section{[Sciento-2019-0007]}

Accept that the verdict on suggested modifications is to be decided by a communal vote that will follow the discussion period.

Have a communal discussion and decide as to what percentage of votes it should take for a modification to be accepted - a simple majority $(50 \%+1)$, or supermajority of three fifths $(60 \%)$, two thirds $(67 \%)$, or three quarters (75\%). Also discuss to decide as to how long the discussion period and the voting period should be.

This modification is incompatible with modification [Sciento-2019-0008].

\section{[Sciento-2019-0008]}

Accept that a countdown mechanism is to be introduced, where a modification is accepted by default if there are no objections within a 90-day period following its publication.

This modification is incompatible with modification [Sciento-2019-0007]. 


\section{References}

Aitkenhead, D. (2013). Peter Higgs: I wouldn't be Productive Enough for Today's Academic System. The Guardian. Friday, December 6, 2013. Retrieved from: https://www.theguardian.com/science/2013/dec/06/peter-higgs-boson-academicsystem

Barseghyan, H. (2015). The Laws of Scientific Change. Springer.

Barseghyan, H. (2018). Redrafting the Ontology of Scientific Change. Scientonomy 2, pp. 13-38. Retrieved from https://scientojournal.com/index.php/scientonomy/article/view/31032.

Bartko, J. J. (1982). The Fate of Published Articles, Submitted Again. Behavioral and Brain Sciences 5(2), pp. 199-199.

Beatty, J. (2018). Consensus: Sometimes It Doesn't Add Up. In Gissis, Lamm, \& Shavit (Eds.) (2018), pp. 179-198.

Birukou, A.; Wakeling, J. R.; Bartolini, C.; Casati, F.; Marchese, M.; Mirylenka, K.; Osman, N.; Ragone, A.; Sierra, C.; \& Wassef, A. (2011). Alternatives to Peer Review: Novel Approaches for Research Evaluation. Frontiers in Computational Neuroscience 5, article 56.

Byrne, D. (2000). Common Reasons for Rejecting Manuscripts at Medical Journals: A Survey of Editors and Peer Reviewers. Science Editor 23(2), pp. 39-44.

Csiszar, A. (2018). The Scientific Journal: Authorship and the Politics of Knowledge in the Nineteenth Century. University of Chicago Press.

Fatigati, M. (2017). A Method for Reconstructing the Medieval Arabic Scientific Mosaic. Scientonomy 1, pp. 19-28. Retrieved from https://www.scientojournal.com/index.php/scientonomy/article/view/27761.

Franco, L.; Rouwette, E.; \& Korzilius, H. (2016). Different Paths to Consensus? The Impact of Need for Closure on ModelSupported Group Conflict Management. European Journal of Operational Research 249(3), pp. 878-889.

Gad-El-Hak, M. (2004). Publish or Perish - An Ailing Enterprise? Physics Today 57(3), pp. 61-62.

Gissis, S.B.; Lamm, E.; \& Shavit, A. (Eds.) (2018). Landscapes of Collectivity in the Life Sciences. MIT Press.

Goode, J. (2016). Eyes Wide Shut: Democratic Reversals, Scientific Closure, and the Study of Politics in Eurasia. Social Science Quarterly 97(4), pp. 876-893.

Horst, M. (2010). Collective Closure? Public Debate as the Solution to Controversies about Science and Technology. Acta Sociologica 53(3), pp. 195-211.

Hunter, J. (2012). Post-Publication Peer Review: Opening Up Scientific Conversation. Frontiers in Computational Neuroscience 6, article 63.

Kluckhohn, C. \& Leighton, D. (1974). The Navaho. Harvard University Press.

Lee, C. (2015). Commensuration Bias in Peer Review. Philosophy of Science 82(5), pp. 1272-1283.

Loiselle, M. (2017). Multiple Authority Delegation in Art Authentication. Scientonomy 1, pp. 41-53. Retrieved from https://www.scientojournal.com/index.php/scientonomy/article/view/28233.

Marsh, H.; Jayasinghe, U.; \& Bond, N. (2008). Improving the Peer-Review Process for Grant Applications: Reliability, Validity, Bias, and Generalizability. American Psychologist 63(3), pp. 160-168.

Meho, L. (2007). The Rise and Rise of Citation Analysis. Physics World 20(1), pp. 32-36.

Musselin, C. (2013). How Peer Review Empowers the Academic Profession and University Managers: Changes in Relationships between the State, Universities and the Professoriate. Research Policy 42(5), pp. 1165-1173.

Novak, S. (2010). Decision Rules, Social Norms and the Expression of Disagreement: The Case of Qualified-Majority Voting in the Council of the European Union. Social Science Information 49(1), pp. 83-97.

Oreskes, N. (2004). The Scientific Consensus on Climate Change. Science 306(5702), p. 1686.

Overgaard, N. (2017). A Taxonomy for the Social Agents of Scientific Change. Scientonomy 1, pp. 55-62. Retrieved from https://www.scientojournal.com/index.php/scientonomy/article/view/28234.

Overgaard, N. \& Loiselle, M. (2016). Authority Delegation. Scientonomy 1, pp. 11-18. Retrieved from https://www.scientojournal.com/index.php/scientonomy/article/view/27065.

Paglia, C. (1992). Sex, Art and American Culture: New Essays. Vintage.

Patton, P; Overgaard, N.; \& Barseghyan, H. (2017). Reformulating the Second Law. Scientonomy 1, pp. 29-39. Retrieved from https://www.scientojournal.com/index.php/scientonomy/article/view/27158.

Phillips, J. (2011). Expert Bias in Peer Review. Current Medical Research \& Opinion 27(12): pp. 2229-2233.

Rawleigh, W. (2018). The Status of Questions in the Ontology of Scientific Change. Scientonomy 2, pp. 1-12. Retrieved from https://scientojournal.com/index.php/scientonomy/article/view/29651.

Ritson, S. (2016). 'Crackpots' and 'Active Researchers': The Controversy Over Links Between arXiv and the Scientific Blogosphere. Social Studies of Science 46(4), pp. 607-628. 
Sebastien, Z. (2016). The Status of Normative Propositions in the Theory of Scientific Change. Scientonomy 1, pp. 1-9. Retrieved from https://www.scientojournal.com/index.php/scientonomy/article/view/26947.

Stanford, K. (2019). Unconceived Alternatives and Conservatism in Science: The Impact of Professionalization, Peer-Review, and Big Science. Synthese 196(10), pp. 3915-3932.

Urfalino, P. (2014). The Rule of Non-Opposition: Opening Up Decision-Making by Consensus. Journal of Political Philosophy 22(3), pp. 320-341. 